\title{
Perancangan Sistem Informasi Laundry Berbasis Web pada Laundry Dian Menggunakan PHP dan Mysql
}

\author{
Delianti Ningsih Allo ${ }^{1}$, Firman ${ }^{2}$, Muhammad Ihsan ${ }^{3}$ \\ Prodi Pendidikan Teknologi Informasi \\ Universitas Pendidikan Muhammadiyah Sorong \\ ningsihdelianti@gmail.com ${ }^{1}$, firmantajdiduliman@gmail.com ${ }^{2}$, \\ muhammadihsanunimudasorong@gmail.com ${ }^{3}$
}

\begin{abstract}
Abstrak: Di era yang serba cepat kebutuhan manusia terhadap waktu membuat semua aktivitas rumah tangga dan masyarakat ingin serba praktis, khususnya seperti mencuci baju. Apalagi bagi orang yang memiliki tuntutan kesibukan dan tidak mempunyai waktu untuk mencuci pakaian, menjemur, dan menyetrika sehingga lebih memilih mempercayakan cuciannya kepada jasa tukang cuci atau laundry dengan alasan menghemat waktu dan agar lebih berkonsentrasi untuk menyelesaikan pekerjaan mereka. Penelitian ini bertujuan untuk merancang sistem informasi pelayanan yang dapat membantu dalam menyampaikan informasi tentang laundry Dian dan mengetahui valid dan efisien sistem informasi pelayanan laundry berbasis web pada laundry Dian. Bentuk penelitian ini menggunakan metode Research and Development (R\&D) untuk menghasilkan sebuah produk dan menggunakan model prototype untuk mendesain sistem. Pada objek penelitian peneliti menggunakan empat metode pengumpulan data berupa wawancara, kuesioner, studi pustaka, dan observasi dengan teknik analisis data statistik deskriptif penyajian data dengan tabel dan perhitungan rata-rata. Berdasarkan hasil penelitian yang telah dilakukan di peroleh nilai 3,8 kategori valid dan di peroleh nilai 3,29 dengan kategori sangat efisien.
\end{abstract}

Kata Kunci: Sistem; Informasi; Laundry; Web; R\&D; Prototype.

\begin{abstract}
In an era where the human need for time was hurried, all domestic and social activities wanted to be practical, especially like laundry. Especially for those who have demands of work and do not have time to wash clothes, dry, and iron so as to prefer to entrust the laundry to a laundry service that saves time and to concentrate more on getting the job done. The study aims to design a service information system that can help in delivering information about laundry and knowing both valid and efficient a web based laundry service information system on laundry. The form of the study USES the research and development method $(r \& d)$ to produce a product and use a prototype model to design systems. Research objects employ four methods of data collection consisting of interviews, questionnaires, library studies, and observations with descriptive data analysis techniques of data presentation with tables and calculations average. Based on the results of the study, it has acquired a valid 3.8 category and a 3.29 value in the most efficient category.
\end{abstract}

Keywords: System; Information; Laundry; Web; R\&D; Prototype. 


\section{Pendahuluan}

Perkembangan teknologi yang semakin maju dan pesat di berbagai bidang saat ini tentu akan berpengaruh pada kemudahan-kemudahan yang diberikan dalam kehidupan sehari-hari sehingga setiap pekerjaan akan semakin mudah dan tertata dengan baik. Teknologi informasi dalam perkembangannya telah menjadi salah satu strategis bisnis yang efektif dan efisien. Hal ini membuat semakin banyak orang yang memanfaatkan perkembangan teknologi untuk menciptakan lapangan pekerjaan sendiri dimana tidak hanya pria yang dapat bekerja namun kaum perempuan ataupun ibu rumah tangga juga mempunyai peluang yang sama untuk berkarir yang dapat dikembangkan di rumah sehingga tidak meninggalkan kewajiban sebagai seorang istri.

Seiring dengan perkembangan zaman yang semakin canggih dan semakin meningkatnya peradaban manusia itu sendiri sehingga membuat manusia selalu termotivasi memperbaharui cara menyampaikan informasi (berkomunikasi) dengan baik dan mudah di akses seperti teknologi dan informatika yang ada saat ini. Sistem informasi sangat memudahkan seseorang dalam melaksanakan atau menyelesaikan pekerjaannya.

Pasal 6 Undang-Undang Republik Indonesia Nomor 11 Tahun 2008 tentang informasi dan transaksi elektronik: "Suatu informasi harus berbentuk tertulis atau asli, informasi elektronik men ggap sah sepanjang informasi yang tercantum dalamnya dapat diakses, ditampilkan, dijamin keutuhannya, dan dapat di pertanggungjawabkan sehingga menerangkan suatu keadaan”. Usaha laundry merupakan salah satu bentuk usaha yang cukup menjanjikan. Di era serba cepat kebutuhan manusia terhadap waktu sangat diperlukan keefektifan kita mengelola dan memanejemen semua aktivitas rumah tangga membuat masyarakat ingin serba praktis, misalnya aktifitas sehari- hari seperti mencuci baju. Apalagi bagi orang yang memiliki tuntutan kesibukan seperti mahasiswa, karyawan dan ibu rumah tangga yang tidak mempunyai waktu untuk mencuci pakaian, menjemur, dan menyetrika sehingga lebih memilih mempercayakan kepada jasa tukang cuci atau laundry dengan alasan menghemat waktu dan agar lebih berkonsentrasi untuk menyelesaikan pekerjaan mereka. Dibalik kemajuan teknologi informasi yang kini telah berkembang secara pesat, sampai saat ini laundry Dian belum memiliki sistem informasi sendiri dan masih menggunakan sistem manual seperti tidak adanya pendataan pelanggan (nama, jumlah kiloan, tanggal masuk, nominal yang harus di bayar), pendataan data transaksi, dan belum mempunyai sistem penyimpanan database yang akurat sehingga semua data masih disimpan kedalam sebuah buku, bahkan pelanggan baik lama maupun baru juga tidak mendapatkan informasi yang up to date tentang berbagai jasa laundry yang ditawarkan serta pelanggan kerepotan pada saat mengantar bahkan saat ingin mengambil laundry di karenakan tidak mempunyai informasi apakah laundry telah selesai.

Seperti yang sudah di jelaskan di atas dalam penelitian ini akan dibuat sistem informasi pendataan dan pengolahan data pelanggan serta data transaksi seperti nota pembayaran agar dapat berjalan cepat dan terekap dengan baik, membantu memudahkan pelanggan dalam memperoleh informasi laundry sehingga dapat memaksimalkan waktu dengan baik. 
Tujuan dari Penelitian ini adalah untuk membantu laundry Dian agar dapat mengetahui kondisi perkembangan usaha, mengelola administrasi secara lebih cepat dan akurat sehingga benar-benar menghasilkan informasi yang tepat, efektif, dan efisien.

\section{Metode Penelitian}

Dalam pembuatan sistem informasi jenis penelitian yang digunakan adalah metode pengembangan $\mathrm{R} \& \mathrm{D}$ (Research and Development) dengan model Prototype. R\&D (Research and Development) merupakan metode yang cocok digunakan dalam sebuah penelitian yang bertujuan untuk menghasilkan sebuah produk. R\&D (Research and Development) terdiri atas dua kata yaitu penelitian dan pengembangan. Kegiatan utama adalah melakukan penelitian dan studi literatur untuk menghasilkan rancangan produk tertentu, dan kegiatan kedua adalah pengembangan yaitu menguji efektivitas, validasi rancangan yang telah dibuat, Sehingga model ini dapat diterapkan pada Perancangan Sistem Informasi Laundry Berbasis Web Pada Laundry Dian Menggunakan $P h p$ dan $M y S Q L$. Sedangkan model pengembangan sistem perangkat lunak yang digunakan peneliti adalah prototype. Alur R\&D dapat dilihat pada gambar 1 .

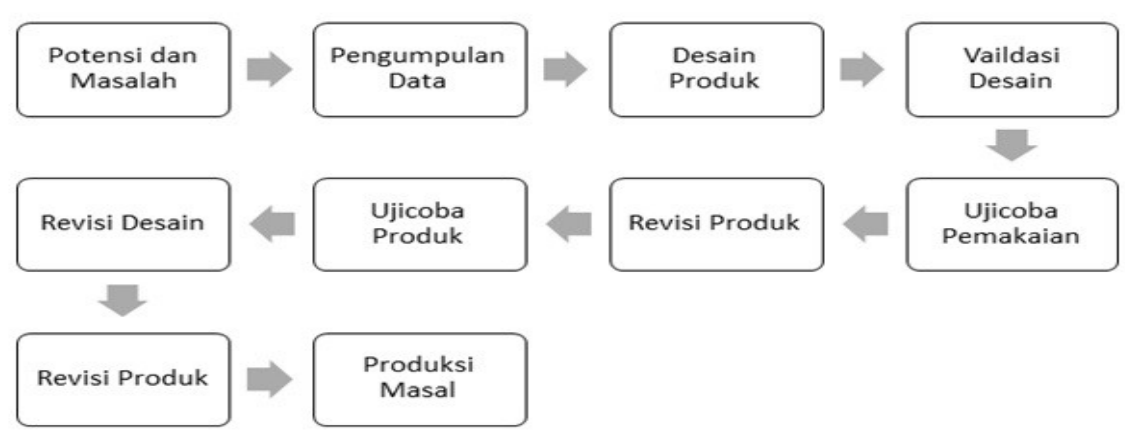

Gambar 1 Tahapan R\&D menurut Sugiyono, 2015

Pada penelitian ini peneliti melakukan 3 metode pengumpulan data agar mendapatkan informasi yang jelas. Pada objek penelitian 4 metode pengumpulan data tersebut adalah sebagai berikut:

1) Wawancara

Wawancara di lakukan agar peneliti mengumpulkan data-data yang berkaitan dengan masalah yang terjadi pada objek penelitian sekaligus mencari solusi dari permasalahan tersebut.

2) Kuesioner

Kuesioner merupakan Teknik pengumpulan data primer yang dilakukan dengan cara menyebarkan seperangkat daftar pertanyaan tertulis kepada responden yang menjadi subjek penelitian, yaitu customer dan admin laundry Dian. Tujuan dari kuesioner ini, untuk mengetahui dan mengukur aspek desain dan kelengkapan fitur dalam sistem informasi laundry berbasis web. Instrumen yang digunakan pada penelitian ini adalah kuesioner skala likert digunakan untuk mengukur sikap, pendapat, dan persepsi seseorang atau sekelompok 
orang tentang fenomena sosial. dengan menggunakan skala likert, maka variable yang diukur dijabarkan menjadi indikator variabel. Kemudian indikator tersebut dijadikan sebagai titik tolak untuk menyusun item-item instrument yang dapat berupa pernyataan atau pertanyaan. Jawaban setiap item instrument mempunyai gradasi dari sangat positif sampai sangat negatif. Jawaban setiap petanyaan sangat baik (SB) bernilai 4, baik (B) bernilai 3, sedang (S) bernilai 2, kurang baik (KB) bernilai 1. Setiap responden diharuskan mengisi jawaban yang telah disiapkan pada tiap pertanyaan dengan cara memberikan tanda check list pada kolom yang telah disiapkan.

3) Studi Pustaka

Studi pustaka untuk melaksanakan penelitian ini di dapatkan dari buku-buku referensi, jurnal nasional serta informasi di internet yang relevan dan sesuai dengan kebutuhan peneliti.

4) Dokumentasi

Metode ini digunakan untuk mendapatkan data berupa dokumen sesuai dengan keadaan lapangan mengenai hal yang berkaitan dengan implementasi sistem informasi laundry berbasis web ..

a. Teknik Analisis Data

menurut Sugiyono (2016:147) Metode analisis deskriptif adalah "Metode statistik yang digunakan untuk menganalisis data dengan cara mendeskriptifkan atau menggambarkan data yang telah terkumpul sebagaimana adanya tanpa bermaksud membuat kesimpulan yang berlaku umum atau generalisasi". Untuk menghitung persentase hasil observasi menggunakan rumus Persamaan.

1. Validitas

Teknik analisis kevalidan ditentukan dengan memberikan skala likers yaitu dengan memberi skor pada jawaban dengan skala sangat baik (4), baik (3), kurang (2), dan sangat kurang (1), lalu menentukan ratarata total validasi menggunakan persamaan validitas oleh (Sudijono, 2011) pada persamaan 1

(Persamaan 3.1)

$$
\bar{V}=\frac{\sum x_{i}}{n}
$$

Keterangan:

$$
\begin{aligned}
& \bar{V} \text { : rata-rata total validasi } \\
& \sum x_{i}: \text { Jumlah skor aspek } \\
& n \quad: \text { banyaknya butir aspek }
\end{aligned}
$$

(Sumber: Widoyoko, 2016) 
Tabel 1 Kategori Validitas

\begin{tabular}{|c|c|c|}
\hline No & Interval & Katagori \\
\hline 1 & $>3,25 \mathrm{~s} / \mathrm{d} 4,0$ & Sangat valid \\
\hline 2 & $>2,25 \mathrm{~s} / \mathrm{d} 3,25$ & Valid \\
\hline 3 & $>1,75 \mathrm{~s} / \mathrm{d} 2,25$ & Kurang valid \\
\hline 4 & $>1,0 \mathrm{~s} / \mathrm{d} 1,75$ & Tidak valid \\
\hline
\end{tabular}

\section{Penilaian efisien}

Kategori penilaian efisien atau menilai kemudahan penggunaan sistem informasi penjualan berbasis web yang dinilai berdasarkan kriteria pengkategorian pada tabel 3.9 kategori efisien. (Sumber: Widoyoko,2016) dapat dilihat pada Tabel 2.

Tabel 2 Kategori Efisien

\begin{tabular}{|c|c|c|}
\hline No & Interval & Katagori \\
\hline 1 & $>3,25 \mathrm{~s} / \mathrm{d} 4,0$ & Sangat efisien \\
\hline 2 & $>2,25 \mathrm{~s} / \mathrm{d} 3,25$ & Efisien \\
\hline 3 & $>1,75 \mathrm{~s} / \mathrm{d} 2,25$ & Kurang efisien \\
\hline 4 & $1,0 \mathrm{~s} / \mathrm{d} 1,75$ & Tidak efisien \\
\hline
\end{tabular}

\section{Hasil dan Pembahasan}

Hasil pengembangan sistem informasi Laundry berbasis web pada Laundry Dian menggunakan PHP dan Mysql menghasilkan sebuah sistem yang dapat membantu pengelola Laundry Dian agar dapat mengetahui kondisi perkembangan usaha, mengelola administrasi secara lebih cepat dan akurat sehingga benar-benar menghasilkan informasi yang tepat, efektif, dan efisien serta membantu pengguna (customer) dalam memperoleh informasi yang berkaitan dengan kegiatan pelayanan jasa pada laundry Dian. Adapun fungsi produk bagi admin adalah sebagai berikut; login, input data karyawan, input data administrasi, input data pelanggan, input data kurir, input data transaksi, input harga jenis layanan, input harga pilihn layanan, input area jarak dan ongkir, input tipe pembayaran, input profil laundry, input syarat dan ketentuan, input syarat dan harga, input laporan. Serta fungsi produk bagi customer adalah sebagai berikut; melakukan pendaftaran, login, lihat harga jenis layanan, lihat harga pilihan layanan, lihat tipe pembayaran, lihat layanan pemesanan, melakukan pemesanan, mencetak nota (invoice), lihat jarak dan area ongkir. 


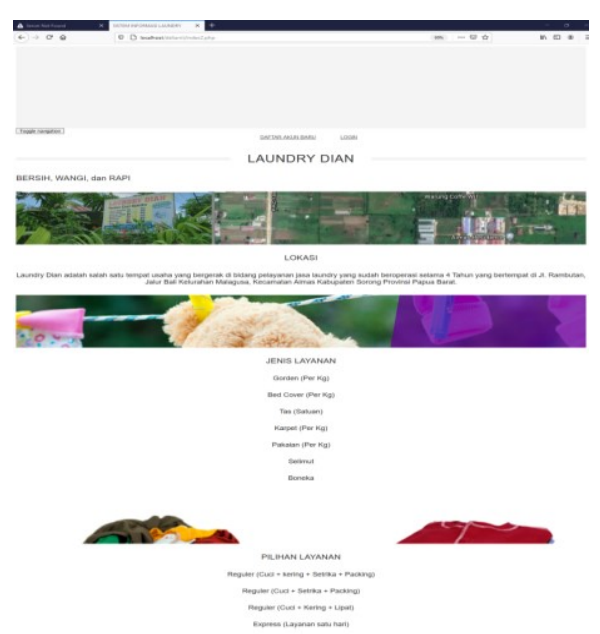

Gambar 3. Tampilan awal admin

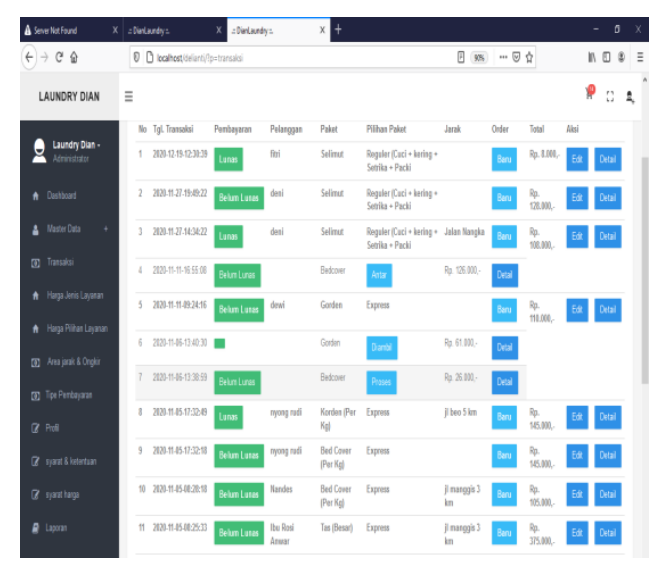

Gambar 5. Tampilan utama admin

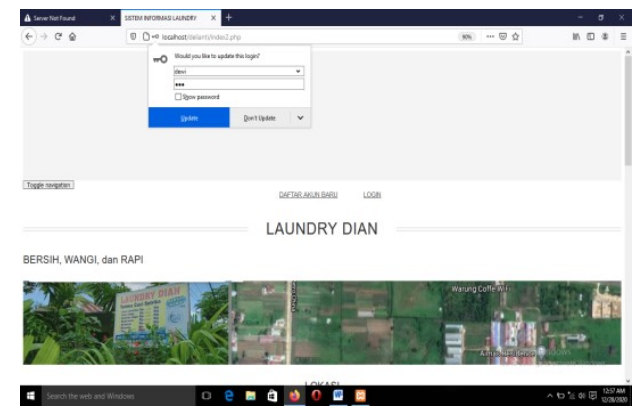

Gambar 7. Tampilan login customer

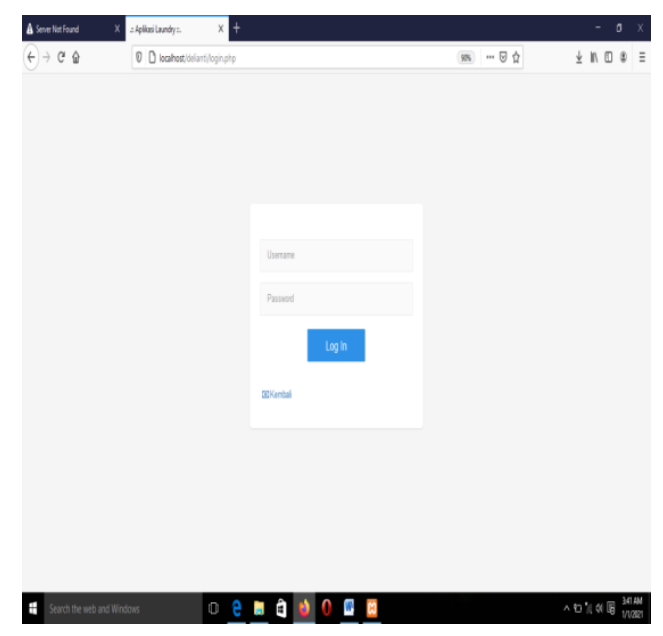

Gambar 4. Tampilan login
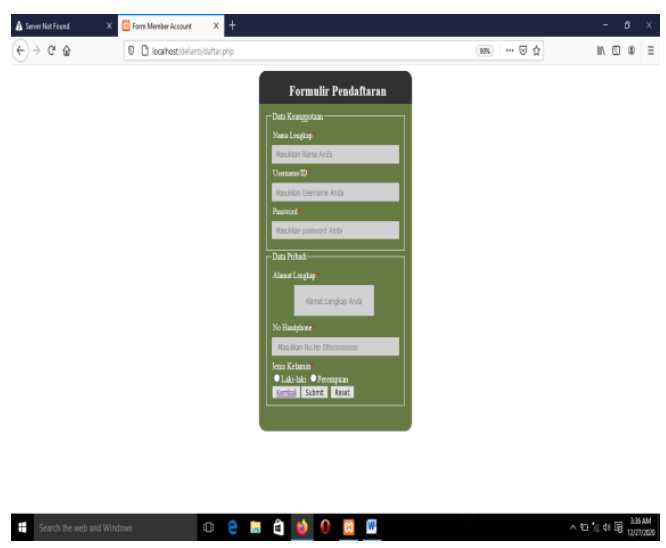

Gambar 6. Daftar baru customer

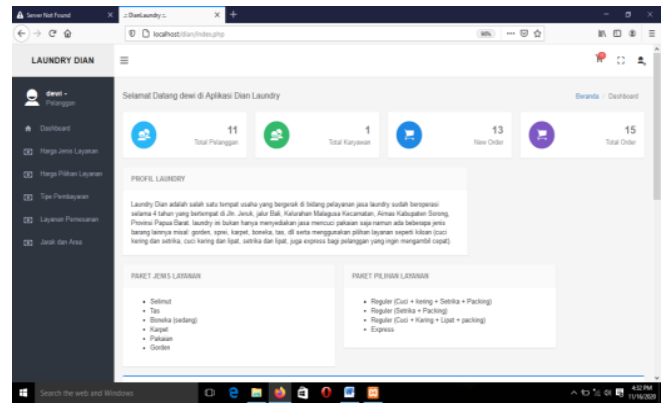

Gambar 8. Tampilan utama customer 
Pengujian dilakukan dengan beberapa cara yaitu pengujian blackbox, pengujian validasi terhadap ahli dan pengujian lapangan.

a. Pengujian Blackbox

Uji coba yang dilakukan untuk mengukur sistem yang telah dibuat menggunakan pengujian blackbox, Pengujian black box pada sistem dibagi menjadi 2 (dua) level user yaitu admin dan customer.

Tabel 3 Pengujian Black Box Admin

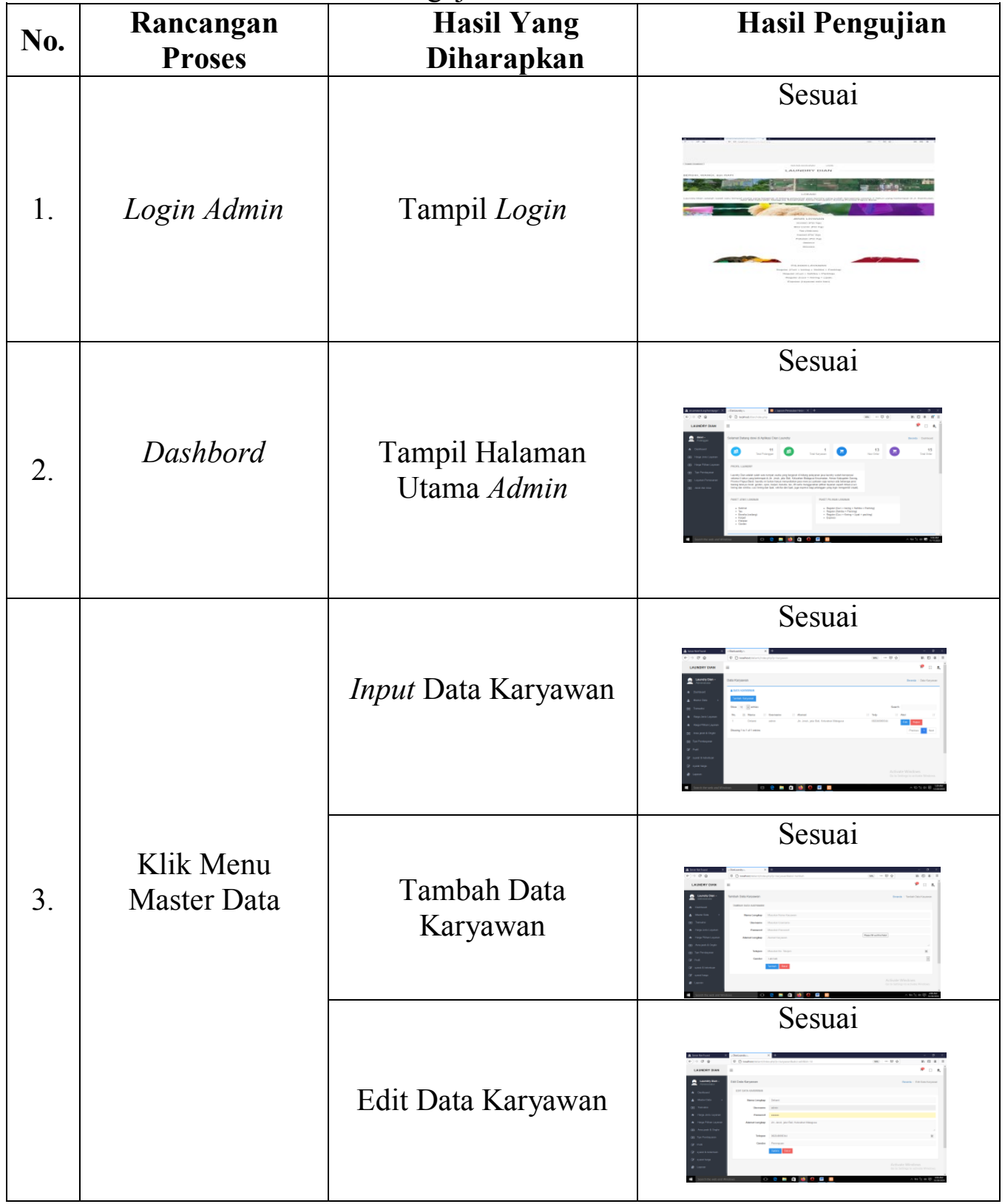




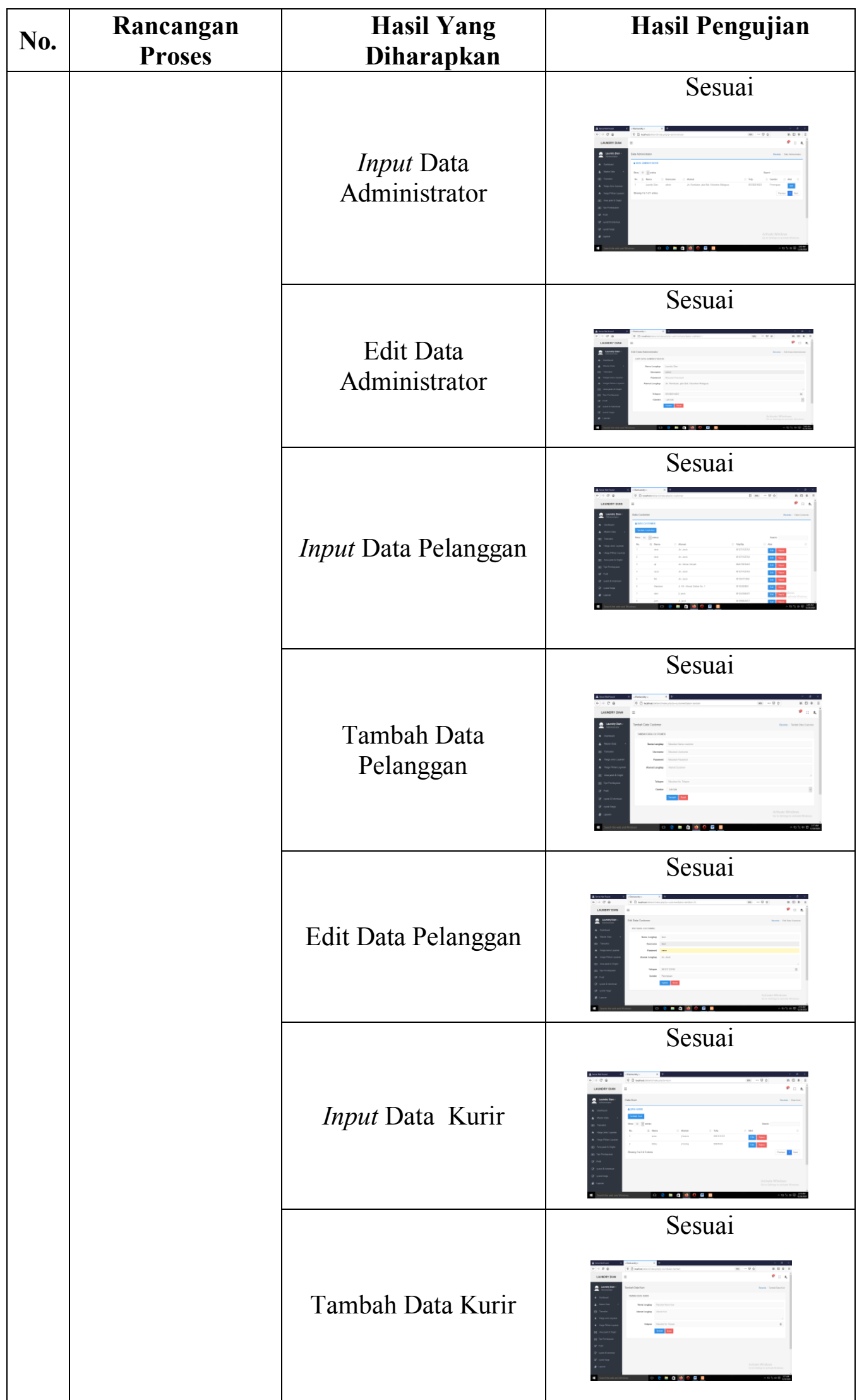




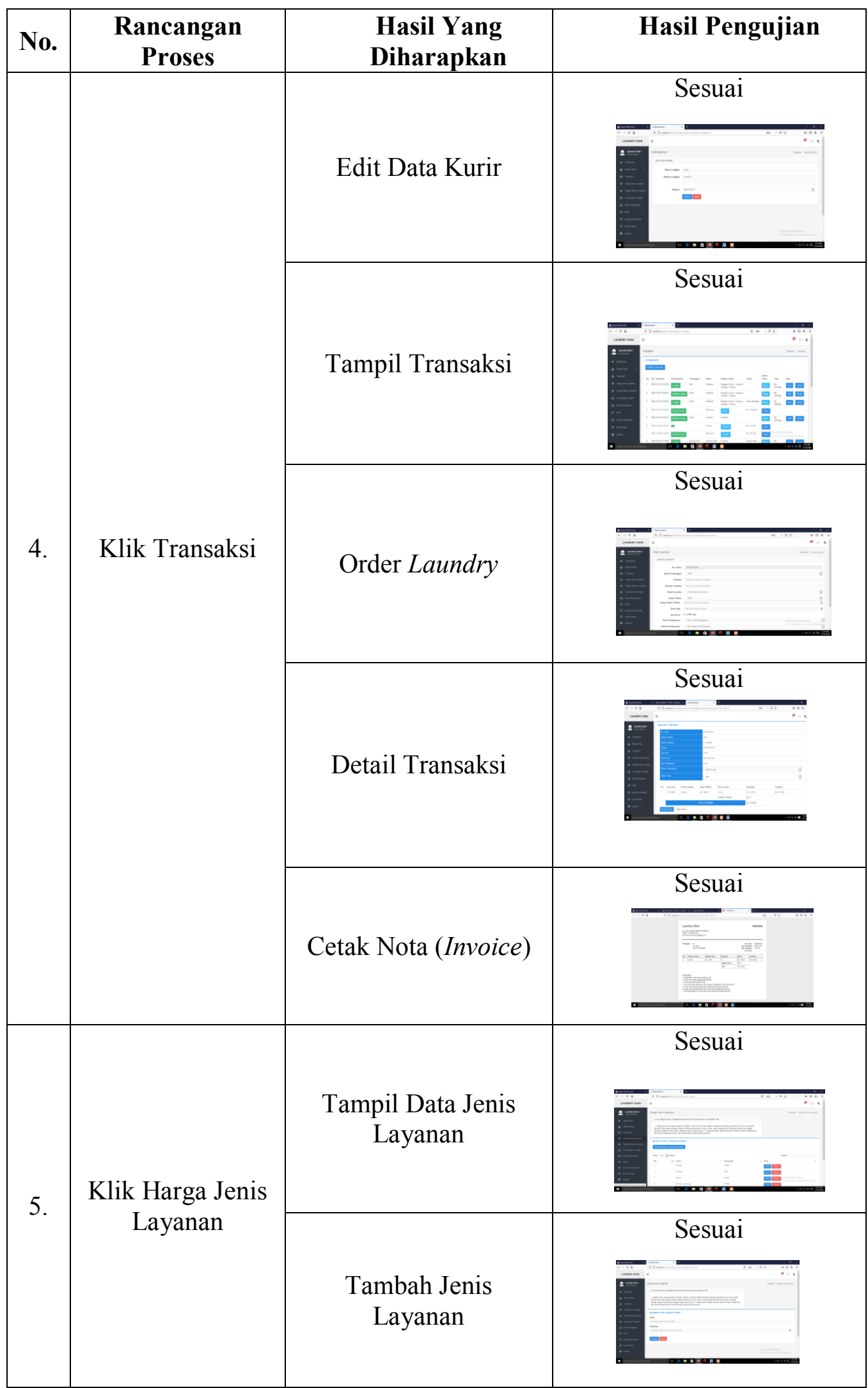




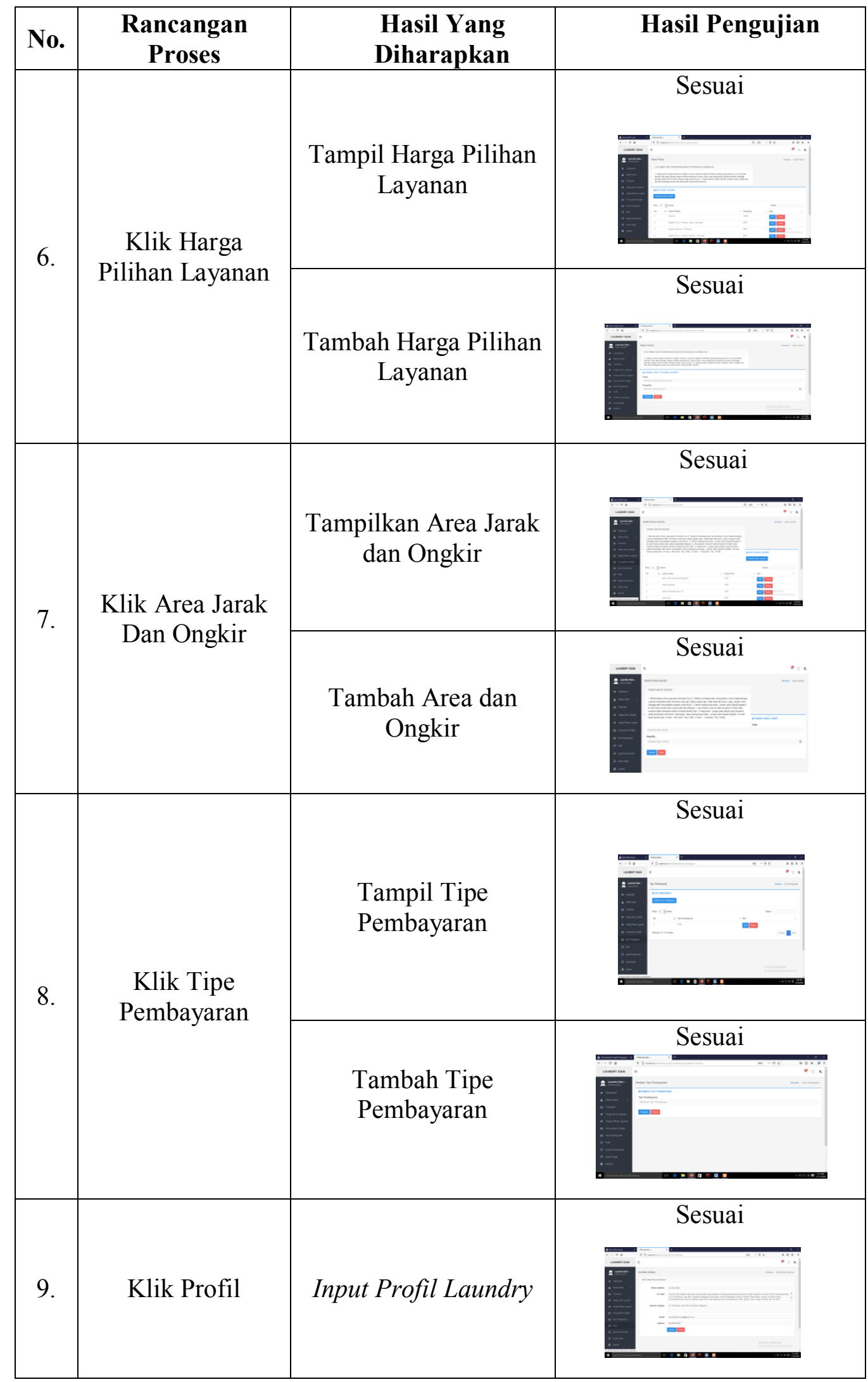


Berdasarkan data dari tabel hasil pengujian black box pada 2 (dua) level user yaitu admin dan customer didapati bahwa setiap halaman yang diuji dan aksi aktor yang dipilih sesuai dengan reaksi sistem yang diharapkan. Setelah tahap pengujian black box dilakukan, maka tahap selanjutnya adalah validasi sistem.

b. Hasil Pengujian Kelompok Besar

Pengujian kelompok besar adalah untuk mencari saran dan penilaian dari subjek berkaitan dengan isi model. Uji coba kelompok besar melibatkan lebih banyak subjek penelitian Perancangan Sistem Informasi Laundry Berbasis Web Pada Laundry Dian Menggunakan PHP dan Mysql digunakan uji kelompok besar sebagai model untuk mengukur keefisiensi sistem dalam penggunaannya yang dilakukan dengan cara memberikan instrument berupa kuesioner kepada 21 responden yaitu antara lain admin dan customer untuk memberikan penilaian terhadap sistem yang sementara berjalan agar menjadi tolak ukur untuk mendapatkan nilai efisien pada sistem. Berikut pertanyaan pada instrument uji efisien yang dapat dilihat pada Tabel 4.

Tabel 4. Pertanyaan Instrumen Efisien

\begin{tabular}{|c|l|c|c|c|c|}
\hline No & \multicolumn{1}{|c|}{ Komponen/Indikator } & \multicolumn{3}{|c|}{ Skor } \\
\hline & \multicolumn{1}{|c|}{1} & 2 & 3 & 4 \\
\hline A. & Kualitas aplikasi & & & & \\
\hline 1. & Mudah dipahami & & & $\checkmark$ & \\
\hline 2. & Mudah digunakan data & & & & $\checkmark$ \\
\hline 3. & $\begin{array}{l}\text { Memudahkan dalam proses penginputan } \\
\text { laundry }\end{array}$ & & & & $\checkmark$ \\
\hline 4. & $\begin{array}{l}\text { Memudahkan dalam proses penginputan data } \\
\text { pelanggan/customer }\end{array}$ & & $\checkmark$ & \\
\hline B & Navigasi & & & & \\
\hline 5. & Kemudahan memilih menu & & & & $\checkmark$ \\
\hline 6. & Kemudahan penggunaan menu & & & & $\checkmark$ \\
\hline 7. & $\begin{array}{l}\text { Ada peringatan jika melakukan kesalahan login } \\
\text { atau input data }\end{array}$ & & & & $\checkmark$ \\
\hline 8. & Kemudahan menginput dan menghapus data & & & & $\checkmark$ \\
\hline C & Penggunaan aplikasi & & & & \\
\hline & Efisien & & & & \\
\hline 9. & Penggunaan aplikasi mengefisienkan waktu & & & $\checkmark$ \\
\hline 10. & Penggunaan aplikasi mengefisienkan tempat & & & $\checkmark$ & \\
\hline 11. & Penggunaan aplikasi memudahkan customer & & $\checkmark$ & \\
\hline 12. & Penggunaan aplikasi mendukung pengolahan & & & $\checkmark$ & \\
\hline & & & & \\
\hline
\end{tabular}




\begin{tabular}{|c|l|c|c|c|c|}
\hline No & \multicolumn{1}{|c|}{ Komponen/Indikator } & \multicolumn{4}{|c|}{ Skor } \\
\cline { 3 - 6 } & & 1 & 2 & 3 & 4 \\
\hline & database laundry Dian & & & & \\
\hline
\end{tabular}

Dari pertanyaan tersebut, diberi keterangan bahwa skor peroleh $1=$ Kurang baik, $2=$ Sedang, $3=$ Baik, dan $4=$ Sangat baik. Berikut penilaian rata-rata dari setiap Kuesioner pada pertanyaan diatas.

Tabel 5 Perhitungan Efisien

\begin{tabular}{|c|c|c|}
\hline No & Nilai & Skor \\
\hline 1 & 3.16 & Efisien \\
\hline 2 & 3.25 & Efisien \\
\hline 3 & 3.08 & Efisien \\
\hline 4 & 3.33 & Efisien \\
\hline 5 & 3.16 & Efisien \\
\hline 6 & 3.16 & Efisien \\
\hline 7 & 3.08 & Efisien \\
\hline 8 & 3.08 & Efisien \\
\hline 9 & 3 & Efisien \\
\hline 10 & 3.5 & Efisien \\
\hline 11 & 3.25 & Efisien \\
\hline 12 & 3.5 & Efisien \\
\hline 13 & 3.25 & Efisien \\
\hline 14 & 3.58 & Efisien \\
\hline 15 & 3.58 & Efisien \\
\hline 16 & 3.41 & Efisien \\
\hline 17 & 3.41 & Efisien \\
\hline 18 & 3.5 & Efisien \\
\hline 19 & 3.33 & Efisien \\
\hline 20 & 3 & Efisien \\
\hline 21 & 3.58 & Efisien \\
\hline Rata-rata & 3,29 & Sangat Efisien \\
\hline
\end{tabular}

Berdasarkan perhitungan instrument pada Tabel 5, maka dengan ini sistem dapat dikatakan sangat efisien dalam kebutuhan mekanisme laundry Dian yang terkomputerisasi dalam sebuah sistem informasi berbasis web. 


\section{Kesimpulan dan Saran}

Dengan menggunakan Perancangan Sistem Informasi Laundry Berbasis Web Pada Laundry Dian Menggunakan PHP dan MySQL, penulis dan pemilik laundry menjadi lebih mudah dalam hal proses pendataan, pengolahan data pelanggan dan data transaksi dapat tersimpan lebih aman dan lebih rapi. Perancangan Sistem Informasi Laundry Berbasis Web Menggunakan $P H P$ dan $M y S Q l$ memiliki penilaian untuk kevalidan yang diperoleh dari instrument penilaian blackbox dan instrument validasi ahli oleh validator dengan nilai 3.8 dengan kategori valid dan penilaian untuk efisien yang diperoleh dari pengisian kuesioner oleh validator dan pengguna yaitu dengan nilai 3.29 dengan kategori sangat efisien.

Adapun saran bagi peneliti selanjutnya: Bagi peneliti selanjutnya yang ingin mengembangkan sistem informasi laundry pada laundry Dian agar dapat menambahkan tombol upload bukti transaksi transfer apabila ingin menambahkan transfer pada tipe pembayaran, dan dapat menambahkan beberapa fitur serta item yang masih belum berfungsi dengan baik.

\section{Daftar Pustaka}

Abdurrosyid, M. (2016). Sistem Informasi Laundry Amanah Samarinda Berbasis Web.

Alda, M. (2019). Sistem Informasi Laundry Menggunakan Metode Waterfall Berbasis Android Pada Simply Fresh Laundry. STMIK Logika, 125-127.

Alfrytian Burhan, M. B. (n.d.). Sistem Informasi Pengolahan Data.

Andriansyah, D. (2018). Penerapan Model Waterfall Pada Sistem Informasi Layanan Jasa Laundry Berbasis Web. Volume 4, No.1 , 27-32.

Evan Susanto, T. H. (n.d.). sistem Informasi Pemesanan Laundry Berbasis Android Di Kota Palembang. Vol. 5, No. 2, Maret 2019, 162-172.

Ghonzali, M. s. (2016). Aplikasi "ILUFA LAUNDRY" Online Menggunakan Framework Codeigniter (Studi Kasus: ILUFA LAUNDRY). Jurnal Manajemen Informatika, Volume 5 Nomor 2 Tahun 2016, 135-142.

Hasan Bisry Isa Alaris, C. A. (2013). Implementasi Black Box testing Pada Sistem Informasi Pendaftaran Santri Berbasis Web Dengan Menggunakan PHP Dan MYSQL. Volume , No. 1, Februari 2013, 23-38.

Helling, L. S. (2018). Perancangan Sistem Informasi Pelayanan Pelanggan Pada Citra Laundry Bogor. INTENSIF, Vol.2 No.1 February 2018, 68-78.

Hoesen, N. (2019). Aplikasi Pelayanan Jasa Pada Laundry Berbasis Android Untuk Meningkatkan Pelayanan Di Bisnis Laundry Pos. Esensi: Jurnal Manajemen Bisnis, Vol. 22 No. 1/ 2019, 28-91.

Margatama, L. (2012). Perancangan Pengembangan Perangkat Lunak Sistem Informasi Laundry Kiloan (SILK). Program Studi Sistem Informasi, Fakultas Universitas Budi Luhur, 8.

Melany, S. M. (2010). Perancangn Industri Jasa Laundry Di Surabaya Selatan. 1 11.

Nasution, M. Y. (2018). Aplikasi Pelayanan Jasa Laudry Berbasis Web (Studi Kasus: Pelangi Laundry Kisaran). Sumatera Utara: Program Studi Teknik Informatika, Fakultas Teknik Universitas Asahan. 
Putri, D. R. (n.d.). Rancangan Bangun Sistem Informasi Manajemen Laundry Pada Khaniaky Laundry.

Pengembangan Sistem Informasi Pelanggan Binatu Berbasis Android Pada Cleaners VIP Laundry Dian. (2018). Vol. 2, No. 12, Desember 2018, 70587066.

Riyanto, S. R. (2019). Sistem Informasi Pengelolaan Data Laundry Pada Rumah Laundry Bekasi. Program Studi Teknik Informatika, Sekolah Tinggi Manajemen Informatika dan Komputer Nusa Mandiri, 8.

Salim, R. R. (2019). Rancang Bangun Sistem Informasi Manajemen Laundry Dalam Pengelolaan Transaksi. 480-483.

Sudijono, A. (2011). Pengantar Evaluasi Pendidikan. Jakarta: Raja Grafindo Persada (Rajawali Press).

Tanto, I. (n.d.). Sistem Informasi Jasa Laundry Pada PT. Tiara Panca Abadi. 6574.

Tjandra, A. K. (n.d.). Perancangan Perangkat Lunak Penerimaan Order Jasa Laundry Berbasis Web. STMIK IBBI, 154-162.

Wulandari, R. R. (2019). Rancangan Aplikasi Laundry Berbasis Deskop Pada Krina Laundry Untuk Wilayah Limo. Teknik Informatika Universitas Pamulang, 52-53.

Yenita Dwi Setiyawati, R. R. (Jurnal teknologi dan Sistem Komputer, Vol.4, No.1,Januari 20116). Pembuatan Aplikasi Antar-Jemput Laundry Berbasis Web Service Pada Platform Android. 150-157.

Zy, A. T. (2017). Sistem Informasi Laundry Pada Wawa Laundry Berbasis Web. Program Studi Teknik Informatika Sekolah Tinggi Teknologi Pelita Bangsa, 152-161. 